\title{
Chinese video streaming services in the context of global platform studies
}

\author{
Wilfred Yang Wang ${ }^{\mathrm{a}}$ and Ramon Lobato ${ }^{\mathrm{b}}$ \\ ${ }^{a}$ School of Media, Film \& Journalism, Monash University, Melbourne, Australia; \\ b School of Media and Communication, Royal Melbourne Institute of Technology \\ University, Melbourne, Australia
}

While recent platform theory within media and communication studies has been developed around U.S.-based examples, platformization has taken a rather different path in China. Focusing on the video streaming service iQiyi, this article asks: What can we learn from approaching Chinese platforms not merely as exception to Western models, but as an opportunity for theory-building around platformization generally? We argue that Chinese online video represents a useful case for rethinking specific elements of platform theory as currently developed in Englishlanguage scholarship. Through a close analysis of iQiyi's interface and regulation, we develop two arguments. The first argument concerns the relationship between regulatory environment, market structure, and platform affordances; and the second concerns platform interfaces, personalization, and fragmentation.

Keywords: video streaming; platform regulation; video on demand (VOD); interfaces; personalization; iQiyi; Netflix

In a recent issue of the journal Asiascape, media scholars Marc Steinberg and Jinying Li pose a provocative argument about the implicit geography of academic research on video platforms (Steinberg \& Li, 2017). Writing against a "dominant mode of platform studies that presume a global geography for US-based examples", Steinberg and Li note the tendency for American platforms to be "taken as models to describe a seemingly placeless intermediary of global (and universal) experiences" (p. 178). In response they offer some alternative suggestions:

What happens when this presumed global geography of US-based platforms is called into question? ... Specifically, how might Asian platforms and the particular cultural negotiations related to them allow us to modify our theoretical basis (and biases) of what a platform is? How can platform studies benefit from a consideration of Japan's Niconico Video, China's Bilibili, or Korea's KakaoTalk? (Steinberg \& Li, 2017, p. 178)

In accepting this challenge to develop models of platform theory that are informed by and responsive to Asian experiences, this article addresses the question of how studying the dynamics of Chinese video streaming platforms can enrich current debates about platforms in general. Our aim is not to approach the Chinese cases as exceptions to Western models, as though they require a separate platform area studies. On the contrary, we explore the possibility that analysis of Chinese services may provide important

*Corresponding author. Email: Wilfred.Wang@monash.edu 
opportunities for theory-building around platforms in general, and thus an opportunity for Chinese media studies expertise to feed more directly into global media studies debates.

We develop this line of inquiry through an analysis of the Chinese video platform iQiyi. Controlled by Baidu, which is the largest search engine provider in China, iQiyi is part of the Baidu, Alibaba, and Tencent (BAT) empire. In 2017, iQiyi entered into a strategic partnership with Netflix to distribute Netflix content in China. However, unlike its American counterpart and other major US-based video platforms, iQiyi is a multipurpose video and lifestyle portal that includes an integrated suite of services from e-lending to online shopping. ${ }^{1}$ iQiyi, which was listed on the NASDAQ in 2018, is also distinctively Chinese in its regulation and political economy. As Curtin and Li (2018, p. 344) note, iQiyi's success is "based not only on technological innovation but also on its ability to mediate between audience aspirations, commercial imperatives, and the enduring power of the Communist state." For these reasons, we consider iQiyi a productive case study for testing and refining ideas about video platforms and their relationship to the state, the market, and the nation.

Rather than mechanistically applying existing theory of video platforms to iQiyi, our approach here is to identify key structural differences between iQiyi and the two platforms most frequently discussed in English-language video platform studies, Netflix and YouTube. These two quite different platforms are chosen as points of comparison not only because of their prominence in the literature but also because of their close relationship to the two media forms - television (Netflix) and social media (YouTube) that are most relevant for understanding iQiyi. We then use the various differences between these services as a foundation for rethinking the presumptive ontology underlying current research on video platforms. This point is illustrated through a close analysis of two aspects of iQiyi: its regulation, and its use of personalization. Based on the results of this analysis, we develop two conceptual arguments about: 1) the relationship between regulatory environment, market structure, and platform affordances; and 2) interfaces, personalization, and fragmentation.

We are mindful of the limitations of this approach. Conducted during late 2017, our analysis of iQiyi is a static snapshot of an evolving infrastructure. Although we have tried to situate these observations in relation to longer trajectories of change, we are aware that iQiyi is dynamic and volatile as are its competitors. We also emphasize that iQiyi is only one video platform among many. Platform theories based on an analysis of Tencent Video or Youku would inevitably be different from those presented here. This article is therefore not about "Chinese media" in general: as Michael Curtin argues, this term must be treated with suspicion because the "unity that one might perceive in such categories results from an uneasy articulation of contingent and unstable elements that have emerged over time" (Curtin, 2012, p. 3). Similarly, Michael Keane's (2015) work reminds us of the enormous heterogeneity of Chinese television, a category that includes not only national networks but also state-owned and entrepreneurial provincial networks that compete against one another and have unique features. Bearing in mind the complexity of categories, such as Chinese "media" and "television," we hope nonetheless that our observations will provide useful analytical principles for scholars who wish to study video streaming services in both China and elsewhere.

\section{Platform Definition, Platform Theory, and the Specificity of Chinese Services}

Even a general definition of the term "platform" depends on one's cultural location. Ping tai literally translates as "interface" or a surface that is raised above its surrounding area, such as a balcony or a deck, and that is built and used for a specific purpose (Xinhua Dictionary, 2018). The term is used in Chinese business discourse to refer to digital 
services, brands, and start-ups, including video platforms, ride-sharing, dating, and social network apps. This usage is broader than in the English-language economics and digital media studies literature on platforms, in which a platform is usually defined either as a multisided marketplace (Evans, 2011) or a computational system upon which other systems can be built (Bogost \& Montfort, 2009). Video streaming services, such as iQiyi, Tencent Video, and Youku, all of which are ping tai, are platforms in the former sense but not necessarily in the latter sense. As multisided marketplaces that integrate viewers, subscribers, advertisers, third-party developers, and other service providers, they enable a wide range of interactions between users, advertisers, and third parties. However, they are not computationally "open" or reprogrammable in the same way as an operating system or gaming console is (Bogost \& Montfort, 2009).

The literature on platforms is vast, spanning several disciplines, such as economics, law, media studies, and sociology. In the English-language media studies research on video platforms, the conversation has developed along two main lines. The first is represented by the growing body of literature on user-generated content sites, especially YouTube, but also including video-enabled social media platforms, such as Twitter, Facebook, and Snapchat. Informed by Internet and new media studies, research in this tradition has tended to focus on questions of user-generated content, online communities, virality, and memes (Burgess \& Green, 2009; Shifman, 2012; Jenkins, Ford, \& Green, 2012). In the most recent scholarship, there is an emphasis on topics such as moderation, monetization, platform governance, and labor (Soha \& McDowell, 2016; Christian, 2018; Gillespie, 2017). In general, this literature is grounded in critical analyses of online communication, discourse, identity, and power. Because of the normative assumption that video platforms either do or should embody ideas of free speech, interaction, and participation, platforms are often criticized if they fall short of these standards (Langvardt, 2017).

A second strand of research on online video platforms extends from film, television, and media studies, as opposed to internet and new media studies. This approach focuses on the implications of digital distribution for existing for screen industries and audiences. Following Amanda Lotz (2017), scholars in this subfield sometimes distinguish portals (i.e., digital delivery storefronts for professional content, such as Netflix and Hulu) from open-access platforms (i.e., video-sharing sites, such as YouTube and Periscope), acknowledging the many structural and experiential differences between these different video services. Issues discussed in this strand of the literature include the new viewing experiences associated with video streaming (Jenner, 2014); algorithmic filtering and recommendation (Madrigal, 2014); and the effects of multiterritory streaming services on national screen markets (Lobato, 2019). ${ }^{2}$

Emerging in parallel to these two strands of research on US-based services, and occasionally overlapping them, is the literature on Chinese video streaming services. Several important studies have appeared in recent years (L. N. Li, 2017; J. Li, 2017; Gu, 2018; E. Zhao, 2017) in addition to the literature on Chinese Internet regulation and digital markets (Fuchs, 2015; Jia \& Winseck, 2018). This body of work has revealed that Chinese video platforms have evolved through several phases of transformation. Often beginning as copycat versions of Western platforms (e.g., Youku), Chinese video services soon developed their own distinctive logics of corporate integration with the aid of funding that was frequently sourced from international venture capital. Although the early years of online video in China were marked by amateur content, grassroots creativity, and mockery of the government (E. Zhao, 2016), the state has since seized the opportunity to utilize digital platforms to advance its domestic and international agendas, such as the "going out strategy" and the "Chinese dream" (Keane, 2016). Copyright enforcement 
campaigns have also brought an end to the "copycat" business model ( $\mathrm{Li}, 2016 ; \mathrm{Gu}$, 2018), and they have enabled crackdowns on politically sensitive user-generated content. Although the history of online video in China is long and complex-with an earlier period of experimentation and openness preceding the rise of IT giants such as Alibaba, Baidu, Sina and Tencent Holding-a fundamental difference that marks this history is the close integration of state and market. ${ }^{3}$ Clearly, China's digital industries have evolved differently from Silicon Valley, and scholars of Chinese online video have developed distinct modes of analysis and historiography to account for this.

Some platform theories that were developed in English-language media studies are loosely transferrable to the Chinese context and vice versa. For example, the body of work on the transformation of online video from a heterogeneous, predominantly amateur content production ecosystem to an increasingly institutionalized, professional content production ecosystem is applicable to both Chinese (see E. Zhao, 2016; Li, 2016; Gu, 2018) and Western video-sharing platforms (Burgess, 2012). However, other differences are less easily accommodated by this theory base. Issues such as platform regulation and political economy are especially resistant to a common theorization. Elaine Zhao (2017), for example, describes the specificities of the Chinese "state-engineered network convergence project" as involving "Power negotiations [that] play out in multiple dimensions, evident in the dynamics between the state and market, between the central and local, and between sectorial interests" (p. 29). This is quite different from how market-platform-state interaction is understood in the literature on U.S. video platforms, which tends to presume limited state intervention restricted to issues like offensive content, child safety, and privacy violations. Regulation, from this perspective, is something that is occasionally done to platforms when they step out of line, or that users and platforms do between themselves (self-regulation/co-regulation). This is quite different from how Chinese internet scholars think about the relationship between state and platform.

Furthermore, Chinese video streaming services do not fit neatly into the categories of platform and portal as they have been established in the screen studies literature. For example, iQiyi is both portal-like (because it foregrounds professional content and established celebrities, offering a strongly curated and programmed TV-like experience) and platform-like (because it provides interactive functions such as online shopping, online payment, e-wallet, e-lending, and upload/sharing of user-generated video). Consequently, it is difficult to map the Chinese services onto a Silicon Valley taxonomy of video services. Additionally, it is not easy to connect these services to the same critical debates that characterize the literature on US-based platforms (Table 1).

[Insert Table 1 here]

Our general point here is that the English-language theory base around video platforms and portals has evolved in a way that is culturally located, and which responds to the specificities and affordances of the services it analyses (especially YouTube and Netflix). This is not necessarily a problem, so long as the cultural location of such research is acknowledged. Theory must always come from somewhere. However, we suggest that caution is needed in analyzing platforms or other digital services using theories that were developed in disparate cultural contexts. Internet scholar Guobin Yang (2014, p. 136), among others, has urged Chinese Internet researchers to emphasize the specific cultural and political contexts from which the Chinese Internet has emerged rather than evaluating the Chinese Internet from the perspective of Western liberal democratic values. In other words, a historically grounded and geographically situated 
understanding of "Internet culture" is needed. ${ }^{4}$ Without overstating the exceptionalism of Chinese services (Keane, 2015) or requiring an entirely new theory of the platform, research on Chinese video services can benefit from some strategic adjustments to certain aspects of existing theories. We will now provide two examples of how this can work in practice.

\section{Recalibrating theories of platform regulation to account for a different ontology of actors}

In English-language Internet studies, liberal values are a constitutive condition underlying much of the research on video platforms. This is certainly the case in the literature on YouTube, as it is in most of the literature on social media, networked democracy, and online public spheres. Characterized by a commitment to free expression and democratic deliberation, this literature arises directly from a liberal democratic context that emphasizes the procedural conditions that safeguard and facilitate democratic values. Similarly, research on the competitive dynamics of online video services in the US context is grounded in an understanding of a particular neoliberal, laissez-faire information economy structure (notwithstanding the many forms of government intervention and state-market collaboration that are actually present within this structure). In other words, a liberal ontology-free speech, free markets-is the constitutive feature of this discourse.

These conditions do not exist in China, at least not in the same way. Scholars of the Chinese Internet do not see communication technologies as being outside the state's political domain; instead, media and communication technologies have always been conceptualized as part of the state's political apparatus (Y. Zhao, 2008). Despite China's economic reform and the marketization of Chinese media since the early 1990s, Chinese media continue to be closely regulated and monitored by the government. Keane (2013), for example, questions the use of "neoliberalism" to describe the transformative experience of the Chinese media system because the government's role remains visible and decisive. This close relationship between state and industry is not unique to China, of course, as precedents exist elsewhere, especially in East Asia. For example, South Korea, a democratic state, has a similar history in which the government encouraged the country's famous chaebols (powerful family-owned enterprises) to invest in technological innovation and digital media (Jin, 2006), with the result that Samsung, SK Holdings, and LG now dominate Korea's digital technology sector as well as its media and cultural industries. Hence, scholars must be careful not to overstate the exceptionalism of China.

\section{[Insert Table 2 here]}

This configuration of state and market can be seen in the structure of the Chinese online video market. Table 2 shows the ownership and partnership structure in this market as it existed in 2015. As shown in Table 2, the most popular video services have come under the effective control of one or another of the BAT companies, which have been aggressively acquiring smaller companies in recent years to expand their market reach and diversify their business interests (Xia \& Fuchs, 2016). This "buying spree" has integrated and consolidated the video market around BAT. Because of the close links between BAT and the state, consolidation brings the video economy further under direct government influence, though it does not of course equate to full control.

Hong's (2017a, 2017b, 2017c) recent work offers important insights into this dynamic. According to Hong, the Chinese state's active presence and frequent 
interventions in the information and communication technology (ICT) market are not performed only for ideological purposes as in the past. These interventions support the growth of national champions through tax incentives, government loans, and restrictions on foreign enterprises. According to Hong (2017c, p. 1,758), "state-business interaction, instead of their opposition, was and continues to be a key variable in the evolving Chinese economy." Indeed, key industry players, such as Baidu's CEO Robin Li and Tencent's Pony Ma are both members of the National People's Congress, which is the supreme decision and policy-making body in China. Furthermore, BAT are expected to contribute to state projects, such as their recent investment in China Unicom. However, the harmony between the Chinese government and its digital champions should not be overstated. As Hong also argues, the "bonds between the state and capital" are "complex, evolving, and contingent" (2017c, p. 1758). Friction is now visible in a number of domains, such as online content censorship, where the state is extending heavy-handed regulation into BAT core business (Arsene, 2018). State-capital relations need, therefore, to be understood as highly "variegated" (Hong 2017c, p. 1761). Hong (2017b, p. 1500) captures this overall dynamic very aptly: "although creating friction, state actions collude with corporate interests on making the Internet an omnipresent vehicle of accumulating and enlisting private and transnational capital".

The nuanced vocabulary of state-market interactions offered by Hong supports our key point that ontologies built on the strong separation between state and market are of limited value when trying to understand the political economy of Chinese digital services. Tools for thinking about Chinese platforms cannot be simply "dragged and dropped" from another context. BAT's aggressive vertical and horizontal expansion would raise concerns in a liberal media environment where the concentration of media ownership is associated with the deterioration of the liberal democratic public sphere. In China, the rapid growth of BAT is supported by the state rather than (or as well as) being a key policy concern of the state. This reflects a different understanding of the role of "media," which is seen by the Chinese government as an engine for collective reform and change rather than a sphere of private enterprise and free communication. Following Hong's argument, we can therefore see how an analytical framework premised on the separation between market and state is poorly suited to analysis of Chinese video platforms.

A second feature of the Chinese online video market, as shown in Table 2, concerns the partnerships between video streaming services' smart TV apps and broadcast television networks. Since 2010, China's content regulations ${ }^{5}$ have stated that all Internet $\mathrm{TV}^{6}$ (wangluo dianshi) service providers must collaborate with one of the seven Internet TV license holders, all of which are state-owned (E. Zhao, 2017). This licensing requirement refers to the streaming platforms' smart TV apps, rather than their websites and smartphone apps; however, the rule has had a profound influence on video service providers' entire content production chain across all platforms. The major effect of the licensing rule is that each video platform must be structurally linked to a statecontrolled television network that provides much of its content. As shown in Table 2, iQiyi is one of the three corporations that have partnered in the Galaxy International TV joint venture, whereas Tencent Video is allied with Southern Media Corporation (SMC). This has significant implications for how online video "programming" is understood in China, which is discussed further in the following section.

Many other layers of regulation also apply to Chinese video services. The management of China's cyberspace is nothing but ambiguous, involving at least four regulating bodies - the Cyberspace Administration of China, the Ministry of Industry and Information Technology, the Ministry of Culture, and the Cyberspace Affairs Council of 
China-each of which issues its own decisions. A fifth regulatory body, the National Radio and Television Administration, ${ }^{7}$ has the ultimate power in regulating all media representation and content both online and offline. Reflecting this complexity, at the bottom of every video streaming website there is a list of, or links to, the many licenses the website operator has obtained. Figure 1 shows the various licenses that iQiyi has obtained (11 in total), which range from a "China Internet Integrity" certification to a food trading permit. Other video streaming services, such as Tencent Video, Youku, and Tudou, display similar certifications. These lists of licenses clearly illustrate the ambiguous and overlapping nature of China's video streaming sector, which includes national, provincial, and local authorities, as well as communications regulators.

[Insert Figure 1 here]

Because of the unique regulatory structure around Chinese video platforms, a different analytical framework is required. Western platform theory is based on a specific ontology of platforms, markets, state, users, communities, and so on, and it presumes some degree of relative autonomy between these elements. From this perspective, regulation is something that happens to platforms after the fact; that platforms and users do to themselves; or, in the most sophisticated models, that evolves as an interactive process between platforms, governments, users, and communities (Gillespie, 2017; Helberger, Pierson \& Poell, 2018). In contrast, Chinese platform theory necessarily begins with an ontology in which state and market are different facets of a common entity. iQiyi, like the other BAT platforms, is a partner within a national cultural and political project, not just an object of regulatory action.

\section{Rethinking personalization debates through analysis of Chinese video services}

A second area of productive tension between the Chinese and Western scholarship on video platforms relates to debates about algorithmic filtering and personalization. Recent research on US-based social media platforms has been increasingly concerned with the propensity for cultural fragmentation because platforms algorithmically tailor their offerings to the interests of each user (Sunstein, 2018). Building on early studies of filter bubbles (Pariser, 2011), scholars are now debating whether this personalization aspect of platform design results in "echo chambers" of like-minded individuals rather than online public spheres. A wider body of research and criticism on "algorithmic culture" has also appeared (e.g., Hallinan and Striphas, 2016; Uricchio, 2018). These concerns find parallel expression in the recent literature on video portals, in which scholars are currently debating the fragmentary effects of algorithmic recommendations. For example, screen scholar Neta Alexander (2016) has critiqued the "mathematization of taste" inherent in personalized Netflix recommendations, while The New York Times columnist Farhad Manjoo (2017) warns that Netflix — with its personalized recommendations tailored to the viewing history of each user- "is deepening our cultural echo chambers" and eroding the "ubiquity" of popular culture.

We suggest that caution is required in importing the argument about personalization to the Chinese context. In China, personalization includes a different set of cultural, industrial, and political implications. At the time of writing, personalized recommendations seem to be used more sparingly on the major Chinese video platforms, although we emphasize that the degree and kind of personalization depends on the category of platform. Dating and shopping apps, for example, are, by necessity, highly personalized. Video platforms, however, vary in their degree of personalization. Usergenerated content apps, such as Douyin (Tik Tok), tailor the interface based on the user's 
viewing history, their followed accounts, and their geo-location (tongcheng in the same city). Furthermore, the major BAT platforms use sophisticated ad-targeting technologies that enable ad targeting to individual users based on their data profiles - an integral feature for ad-supported free video platforms like Youku and iQiyi (Keane \& Su, 2018). This "behind the scenes" personalization, based on ad-targeting and consumer tracking, is extensive and sophisticated, and it has led to concerns that digital platforms in China may exacerbate existing inequalities between different social groups, especially between urban and rural populations, ${ }^{8}$ by offering them qualitatively different experiences, opportunities, and service levels.

The iQiyi platform is an interesting case because it reflects some but not all of these tendencies toward personalization. Although the platform targets ads at individual users, iQiyi's interface is still remarkably less personalized than other major Chinese platforms and certainly less so than its closest US equivalents, YouTube and Netflix. To understand why, we examine the iQiyi interface using the "walkthrough method" developed by Light, Burgess, and Duguay (2016). ${ }^{9}$

Unlike Netflix and YouTube, iQiyi does not adjust its categories according to each user, and there appears to be limited personalization of the videos within each category. In other words, at the time of writing, most iQiyi users have seen more or less the same thing when they "fire up" the app or website. Most personalized elements, including recently watched and saved videos, are found in the "My VIP" section for paid subscribers. Even within the My VIP section, the personalization (ge ren) banner is not the kind of personalization that emphasizes the individuality of users; it has more to do with providing functions that allow users to have all their daily routines, from shopping, to reading books, to playing games and even connecting with others (timelines), available on iQiyi.

It is also worth emphasizing how "busy" iQiyi may appear compared with Western interfaces. The layout is cluttered, visually excessive, and the content appears to spread in all directions. This is a common feature of East Asian platforms, especially Japanese and Chinese ones. US-based platforms, however, prefer a minimalist aesthetic (e.g., Netflix, Airbnb, Facebook). Notably, each iQiyi vertical category has a distinctive "look": one for film and drama video, another for lifestyle advice and information (maternal, cars, and health), and a transactional design in the app store and shopping section. However, despite this aesthetic variation, the recommended content in each vertical remains relatively stable from one user to another.

In summary, iQiyi's interface indicates a different understanding of its users in comparison with the major US platforms. iQiyi does not imagine its users as sovereign individuals with unique tastes that the platform must do its best to satisfy. It is not based on a cultural logic of personal taste. In the iQiyi interface, the fragmentary effect of personalized recommendations is replaced by a traditional, structured design that emphasizes the browsing of categories and verticals. In other words, iQiyi seeks to integrate its diverse audience into a common, shared, stable online television experience - in which all viewers are offered the same news, current affairs and celebrity gossip - and to didactically guide viewers towards useful content. In this sense, iQiyi is structurally closer to an online television service than an algorithmically curated digital library or a highly personalized online video site. In the Western context, its closest parallels would be television portals, such as CBS.com or BBC iPlayer rather than YouTube or Netflix.

To illustrate this point, consider the following examples. iQiyi features an extensive maternal care (muying) section, which is constructed explicitly as a curated civic and educational resource provided by "popular experts" (Lewis, Martin, \& Sun, 
2016). Rows of graphic icons indicate subcategories and search filters corresponding to the various stages of pregnancy and childhood in addition to important child-rearing information regarding baby health, early childhood education, and nutrition. Overall, the platform design evokes an online instructional manual that guides individuals step-bystep through key life stages. iQiyi goes to great lengths to convey a sense of expert authority here: presenters are dressed in white medical robes, and their qualifications are listed. Meanwhile, a narrator explains everything in a steady, authoritative tone of voice. iQiyi's interface and the content of the videos reinforces the advice-seeking discourse of this section, in which the platform performs a paternalistic function of information provision for the presumed female citizen/consumer. Several other sections of the platform are also constructed in this fashion. For example, in the cars section, the filters of the car model and make are prominently placed at the top of the screen, which encourages users to "select and search" rather than randomly scroll and browse. The emphasis is on what the user should know, not what the user wants to see. Whereas YouTube once offered the ability to "broadcast yourself," and Netflix promises to know its users better than they know themselves. iQiyi's abiding logic is quite different: it seems to say, "let us guide you to find yourself."

The paternalistic discourse is further exemplified by iQiyi's extensive news and current affairs section, located near the top of its home screen. This section includes numerous videos of party leaders' speeches, current affairs, entertainment news, and celebrity gossip. In the context of U.S.-based video platforms, this arrangement would be considered unusual. Services such as YouTube or Netflix do not have their own news services, and they do not seek to replicate news genres that are associated with broadcast television. In contrast, iQiyi is strongly "TV-like" in its emphasis on capturing the national mood, agenda-setting, and providing a shared set of cultural materials to all viewers. One cannot speak of iQiyi being outside the mainstream media industries, in the same way that YouTube and Netflix can be seen as "digital disruptors" taking on the U.S. TV networks. As reflected in its interface design, iQiyi is not outside the Chinese mass media system; it is an extension of mass media into the online space.

It is worth emphasizing that content exclusivity has not been a dominant theme in the Chinese video economy. Indeed, the iQiyi news and current affairs section includes content that is shared across many other video streaming sites in China. Users, regardless of whether they prefer iQiyi, Youku, or Tencent Video, have a strong sense of the national "news of the day" because the services carry much the same content. For example, our research was conducted during the Lunar Chinese New Year in 2018 (15 February to 2 March), and President Xi Jinping made the traditional New Year greeting on the first day of the Lunar New Year. This content was soon available across all three of the BAT video streaming platforms (iQiyi, Tencent Video, and Youku). A short online video produced by CCTV, Family, Nation and the World (jiaguo tianxia) - which correlates traditional family values with national strength, and in which the President features quite prominently-was also released across all three video platforms. The cross-platform availability of this video underscores what Chinese media scholars have long observed about the media "fulfilling" the Party line by incorporating the state's ideological manifestoes into their daily operations (Y. Zhao, 2008). Despite the democratic and decentralized promised of the Internet in a Western context, the process of digitization has little changed the political duty-fulfillment practice of Chinese media.

The logic of iQiyi is therefore closer to an older model of broadcast television programming than it is to algorithmic personalization. Although iQiyi has announced its intention to move toward a personalized interface style in the future (iQiyi, 2018), at the time of writing, it remains relatively uniform in its mode of address. This is partly a 
consequence of the regulatory structure in China, which defines video streaming as part of the country's broadcasting content system and which requires partnerships with online television license holders. As we have shown, the structural integration between new and old media takes a visible form in iQiyi's interface, which rejects the Silicon Valley model of algorithmic curation in favor of a newspaper and broadcast-like organizational structure. The tendency toward a more collectivist, "mass media" orientation provides an important counterpoint to dominant strands of media theory in which platforms are associated with fragmentation, personalization, and individualization. The case of iQiyi suggests that platforms can integrate, as well as fragment, a mass audience.

\section{Conclusion}

In this paper we have analysed iQiyi and its difference from U.S.-based video platforms. Our aim has been to speak across the literatures dealing with Chinese and U.S.-based video platforms, and to think about what their underlying ontologies reveal or obscure about the relationship between platforms, markets, and the state. Through a discussion of China's online video sector, we explored the historical legacies and geographical specificities conditioning the operation, structure, and governance of video platforms. Our approach has not been only to offer a conventional post-colonial critique or to "dewesternize" platform studies. Instead, we sought to draw out some of the macro-level legacies and logics that shape the micro-level operations of platforms.

Our analysis revealed the ways in which iQiyi has responded to the conflicting forces that drive Chinese platformization. iQiyi must heed the state's political imperative to maintain uniformity in services and content formats across its diverse user base and to provide a TV-like, national mode of address. Its use of hyper-individualized personal recommendations has therefore been rather limited. Although iQiyi may change in the future, until now it has taken a different path from its US-based equivalents, and indeed from some other Chinese video platforms. The implication here is that the taken-forgranted critical concepts associated with digital platforms, such as individualization, decentralization, user empowerment, and disruption, may have limited application in the case of iQiyi.

Studies of Chinese platforms should not only describe their features within a narrow national frame. A preferable alternative, which we have tried to develop here, is a spatialized platform theory that is sensitive to the historical origins of particular platforms, the ways in which these contexts inform the interface designs of platforms and their discrepant trajectories throughout the world. ${ }^{10}$ This approach may sometimes involve shifting the frame of reference from a default liberal democratic ontology of free speech and free markets to one that is sensitive to the specificities of other historical processes and media systems. By understanding the latent structuring of platforms as institutions in their local regulatory, cultural, and political contexts, we might be able to rethink both the definition of a platform and the media environment from whence it emerges.

\section{Notes}

1. In January 2016, iQiyi changed its name from iQiyi Video to iQiyi, reflecting its wider ambition as an integrated, multifunctional platform. The bottom of the desktop website features a list of "partners," which include various Baidu businesses: Baidu video, Baidu-pedia, Baidu forum (tieba), hao123 and iQiyi Tmall. If we follow the "Commercial Town" link, we arrive at a fully featured online retail service selling a 
wide variety of consumer goods, which would be quite unusual on a video platform in the West.

2. Between these two strands of the literature, one finds books such as Social media entertainment (Cunningham \& Craig, 2018), which draw on both analytic approaches.

3 . The growth of the Chinese Internet was facilitated through a campaign of hypernationalism orchestrated by the government in response to the $1999 \mathrm{NATO} / \mathrm{US}$ airstrike of the Chinese embassy in the former Yugoslavia (Wu, 2007).

4. Examples can be found in the well-known studies of the origins of Californian cyber culture by Barbrook and Cameron (1996) and Turner (2006).

5. The licensing requirement is described in two separate documents issued by the SARFT in 2010: Internet TV content service regulation standard and Internet TV Industries Management Standard (Sheng, 2010).

6. The broad term Internet TV (wangluo dianshi) therefore encapsulates nearly all forms of content production, ranging from films and drama, to entertainment, documentary, sport, and even education genres, which replicate the traditional television sector in China.

7. Formerly the State Administration of Press, Public, Radio, Film, and Television (SAPPRFT) until early 2018.

8. The "elite discourse" and the structural inequality between rural and urban populations embody, first, the economic question of market failure, and, second, a political challenge to the state's ambition to govern using digital technologies (Hong, 2016). To address the issue of inequality, industry players were desperate to develop entertainment-focused, banal services, such as online gaming and video on demand, which require little or no technical skills from their users. The state has been supportive of these leisure- and entertainment-driven initiatives (Hong, 2016). However, while the digital divide remains at the level of hardware and access, there is increasing national uniformity at the service level. Tom McDonald's (2016) research on social media in rural China provides compelling evidence that BAT have penetrated the rural areas of China as well as the cities.

9. The first step in the walkthrough method is to identify an app's "vision, operating model and [internal] governance" before scrutinizing "technological mechanisms and embedded cultural references to understand how [the interface] guides users and shapes their experiences" (2).

10. This way of thinking about platforms has already appeared in the anthropological literature (Miller et al., 2016), which is highly attentive to the variability of platform use across national contexts. Research initiatives, including the Global Internet TV Consortium (global-internet-tv.com) explore this variability specifically in relation to video streaming services.

\section{Notes on contributors}

Wilfred Yang Wang is a lecturer in communications \& media studies at Monash University, Melbourne. His research interests include digital geography, Chinese media, the migrant Internet, and the sociology of death and memorialization. His recently completed book, Digital media in urban China, traces the geographical and historical logics of digital culture in China (under contract with Rowman \& Littlefield International).

Ramon Lobato is a senior research fellow at RMIT University, Melbourne. His research interests include video markets, distribution, and piracy. He is the author of Shadow 
economies of cinema (BFI, 2012), The informal media economy (Polity, 2015), and Netflix nations (NYU Press, 2019).

\section{References}

Alexander, N. (2016). Catered to your future self: Netflix's "predictive personalization" and the mathematization of taste. In K. McDonald \& D. Smith-Rowsey (Eds.), The Netflix effect: Technology and entertainment in the 21st century (pp. 81-97). London: Bloomsbury.

Barbrook, R., \& Cameron, A. (1996). The Californian ideology. Science as Culture, 6(1), 44-72.

Bogost, I., \& Montfort, N. (2009). New media as material constraint: an introduction to platform studies. HASTAC 2007 conference proceedings. Retrieved from https://www.hastac.org/electronic-techtonics-breakout-sessions/ian-bogost-andnick-montfort-new-media-material-constraint

Burgess, J. (2012). YouTube and the formalisation of amateur media. In D. Hunter, R. Lobato, M. Richardson, \& J. Thomas (Eds.), Amateur media: Social, cultural and legal perspectives (pp. 53-58). London: Routledge.

Burgess, J., \& Green, J. (2009). YouTube: Online video and participatory culture. Cambridge: Polity.

Christian, A. J. (2018). Open TV: Innovation beyond Hollywood and the rise of web television. New York: NYU Press.

China Internet Watch. (2017, April 28). Top mobile video apps in China in March 2017. Retrieved from https://www.chinainternetwatch.com/20472/mobile-video-appsmar-2017/

Cunningham, S., \& Craig, D. (2019). Social media entertainment: The new intersection of Hollywood and Silicon Valley. New York: New York University Press.

Curtin, M. (2012). Chinese media and globalization. Chinese Journal of Communication, 5(1), 1-9.

Curtin, M., \& Li, Y. (2018). iQiyi: China's internet tigers take television. In D. Johnson, (Ed.), From networks to Netflix: A guide to changing channels (pp. 343-354). New York and London: Routledge.

Evans, D. S. (2011). Platform economics: Essays on multi-sided businesses. Lexington, KY: CreateSpace.

Fuchs, C. (2015). Baidu, Weibo and Renren: The global political economy of social media in China. Asian Journal of Communication, 26(1), 14-41.

Gillespie, T. (2017). Governance of and by platforms. In J. Burgess, T. Poell, \& A. Marwick (Eds.), The Sage handbook of social media. Thousand Oaks: Sage.

Gu, J. (2018). From divergence to convergence: Institutionalization of copyright and the decline of online video piracy in China. International Communication Gazette, 80(1), 60-86.

Hallinan, B., \& Striphas, T. (2016). Recommended for you: The Netflix Prize and the production of algorithmic culture. New Media \& Society, 18(1), 117-137.

Helberger, N., Pierson, J., \& Poell, T. (2018). Governing online platforms: from contested to cooperative responsibility. The Information Society, 34(1), 1-14.

Hong, Y. (2017a). Networking China: The digital transformation of the Chinese economy. Urbana, Chicago, and Springfield: University of Illinois Press.

Hong, Y. (2017b). Pivot to Internet Plus: Molding China's digital economy for economic restructuring? International Journal of Communication, 11, 14861506. 
Hong, Y. (2017c) Reading the 13th Five-Year Plan: Reflections on China's ICT policy. International Journal of Communication, 11, 1755-1774.

iQiyi. (2018, July 5). iQIYI's CTO remarks on the importance of AI to the entertainment industry at TechCrunch Hangzhou [press release]. Retrieved from https://www.prnewswire.com/news-releases/iqiyis-cto-remarks-on-theimportance-of-ai-to-the-entertainment-industry-at-techcrunch-hangzhou300676533.html

Jenkins, H., Ford, S., \& Green, J. (2012). Spreadable media: Creating value and meaning in a networked culture New York: NYU Press.

Jenner, M. (2016). Is this TVIV? On Netflix, TVIII and binge-watching. New Media \& Society, 18(2), 257-273.

Jia, L., \& Winseck, D. (2018). The political economy of Chinese internet companies:

Financialization, concentration, and capitalization. International Communication Gazette, 80(1), 30-59.

Jin, D. Y. (2006). Cultural politics in Korea's contemporary films under neoliberal globalization. Media, Culture \& Society, 28(1), 5-23.

Keane, M. (2013). Creative industries in China: Art, design and media. Cambridge, UK: Polity Press.

Keane, M. (2015). The Chinese television industry. Basingstoke: British Film Institute/Palgrave.

Keane, M. (2016). Disconnecting, connecting, and reconnecting: how Chinese television found its way out of the box. International Journal of Communication, $10,5426-5443$.

Keane, M. \& Su, C. (2018). The will to power: The BAT in and beyond China. In M. Keane, B. Yecies, \& T. Flew (Eds.), Willing collaborators: Foreign partners in Chinese media (pp. 47-62). London and New York: Rowman \& Littlefield International.

Langvardt, K. (2017). Regulating online content moderation. Georgetown Law Journal, 106, 1353-1388.

Lewis, T., Martin, F., \& Sun, W. (2016). Telemodernities: Television and transforming lives in Asia. Durham: Duke University Press.

Li, J. (2017). The interface affect of a contact zone: Danmaku on video-streaming platforms. AsiaScape: Digital Asia, 4(3), 233-256.

Li, L. N. (2016). Rethinking the Chinese internet: Social history, cultural forms, and industrial formation. Television \& New Media, 18(5), 393-409.

Light, B., Burgess, J., \& Duguay, S. (2016). The walkthrough method: An approach to the study of apps. New Media \& Society, 20(3), 881-900.

Lobato, R. (2019). Netflix nations: The geography of digital distribution. New York: New York University Press.

Lotz, A. (2017). Portals: A treatise on internet-distributed television. Michigan: Maize Publishing.

Madrigal, A. (2014, January 2). How Netflix reverse engineered Hollywood. The Atlantic. http://www.theatlantic.com/technology/archive/2014/01/how-netflix-reverseengineered-hollywood/282679/

Manjoo, F. (2017, January 11). How Netflix is deepening our cultural echo chambers. New York Times. Retrieved from https://www.nytimes.com/2017/01/11/technology/how-netflix-is-deepening-ourcultural-echo-chambers.html

McDonald, T. L. (2016). Social media in rural China: Social networks and moral 
frameworks. London: UCL Press.

Miller, D., Costa, E., Haynes, N., McDonald, T., Nicolescu, R., Sinanan, J., Spyer, . . Wang, X. (2016). How the world changed social media. London: UCL Press.

Noble, S. (2018). Algorithms of oppression: How search engines reinforce racism. New York: NYU Press.

Pariser, E. (2011). The filter bubble: What the Internet is hiding from you. London: Penguin Books.

Quest Mobile. (2015, January 27). Observing video streaming apps 2014: The emergence of the three main camps. Retrieved from http://www.questmobile.com.cn/blog/blog-5.html

Sheng, H. (Ed.). (2010, April 27). The SARFT will launch the internet TV content licensing system to better regulate online content (Guangdian zhongju jiang fa hulianwang dianshi neirong paizhao naru yange jianguan). People's Daily. Retrieved from http://media.people.com.cn/GB/193277/193278/11992756.html

Shifman, L. (2012). An anatomy of a YouTube meme. New Media \& Society, 14(2), 187-203.

Soha, M., \& McDowell, Z. J. (2016). Monetizing a meme: YouTube, Content ID, and the Harlem Shake. Social Media + Society, 2(1), 1-12

Steinberg, M., \& Li, J. (2017). Introduction: Regional platforms. Asiascape: Digital Asia, 4(3), 173-183.

Sunstein, C. (2018). \#Republic: Divided democracy in the age of social media. Princeton: Princeton University Press.

Turner, F. (2006). How digital technology found utopian ideology: Lessons from the first hackers' conference. In D. Silver \& A. Massanari (Eds.), Critical cyberculture studies (pp. 257-269). New York and London: New York University Press.

Uricchio, W. (2018) Data, culture and the ambivalence of algorithms. In M. T. Schäfer \& K. van Es (Eds.), The datafied society: Studying culture through data (pp. 125138). Amsterdam: Amsterdam University Press.

van Dijck, J. (2013). The culture of connectivity: A critical history of social media. New York: Oxford University Press.

$\mathrm{Wu}, \mathrm{X}$. (2007). Chinese cyber nationalism: Evolution, characteristics, and implications. Lanham, MD: Lexington Books.

Xia, B., \& Fuchs, C. (2016). The financialisation of digital capitalism in China. Westminster Advanced Studies, 4, 1-32. Retrieved from https://www.westminster.ac.uk/file/87756/

Xinhua Dictionary. (2018). Ping Tai (platform). Retrieved from http://xh.5156edu.com/html5/z31m38j345267.html

Yang, G. (2014). Political contestation in Chinese digital spaces: Deepening the critical inquiry. China Information, 28(2), 135-144.

Zhao, Y. (2008). Communication in China: Political economy, power, and conflict. Lanham, MD: Rowman \& Littlefield.

Zhao, E. J. (2016). The professionalization of amateur production in online screen entertainment in China: Hopes, frustrations and uncertainties. International Journal of Communication, 10, 5444-5462.

Zhao, E. J. (2016). The bumpy road towards network convergence in China: The case of over-the-top streaming services. Global Media and China, 2(1), 28-42. 


\section{Tables}

Table 1

Video Platforms, Portals, and Associated Critical Debates

\begin{tabular}{|l|l|l|l|l|}
\hline Service & Type & $\begin{array}{l}\text { Signature } \\
\text { content }\end{array}$ & $\begin{array}{l}\text { Dominant mode of Key debates } \\
\text { access }\end{array}$ \\
\hline YouTube & Platform & $\begin{array}{l}\text { Semi-professional } \\
\text { UGC }\end{array}$ & $\begin{array}{l}\text { Free (advertising-based), } \\
\text { with premium tier and } \\
\text { transactional purchases }\end{array}$ & $\begin{array}{l}\text { User creativity; } \\
\text { moderation; fake } \\
\text { news }\end{array}$ \\
\hline Netflix & Portal & $\begin{array}{l}\text { Professional film } \\
\text { and TV }\end{array}$ & $\begin{array}{l}\text { Paid (subscription) } \\
\text { ringe viewing; } \\
\text { systems; } \\
\text { personalization }\end{array}$ \\
\hline iQiyi & Hybrid & $\begin{array}{l}\text { Professional film } \\
\text { and TV; some } \\
\text { UGC }\end{array}$ & $\begin{array}{l}\text { Free (advertising-based), } \\
\text { with premium tier and } \\
\text { transactional purchases }\end{array}$ & (Emerging) \\
\hline
\end{tabular}

Table 2

The Online Video Sector in China Circa 2015

\begin{tabular}{|c|c|c|c|c|}
\hline Service/app & $\begin{array}{l}\text { Monthly } \\
\text { active } \\
\text { users } \\
\text { (millions) }\end{array}$ & $\begin{array}{l}\text { Daily active } \\
\text { users } \\
\text { (millions) }\end{array}$ & Ownership* & $\begin{array}{l}\text { Partnered TV } \\
\text { license holder }\end{array}$ \\
\hline iQiyi & 160 & 35 & Baidu & $\begin{array}{l}\text { Galaxy } \\
\text { International } \\
\mathrm{TV}\end{array}$ \\
\hline Youku & 160 & 40 & Alibaba & $\begin{array}{l}\text { Wasu Media } \\
\text { Hangzhou } \\
\text { Broadcasting } \\
\text { Corporation }\end{array}$ \\
\hline Tencent Video & 150 & 36 & Tencent & $\begin{array}{l}\text { Southern } \\
\text { Media } \\
\text { Corporation }\end{array}$ \\
\hline Sohu Video & 56 & 12 & Sohu & $\begin{array}{l}\text { Southern } \\
\text { Media } \\
\text { Corporation }\end{array}$ \\
\hline PPTV & 54 & 12 & Alibaba & Wasu Media \\
\hline Storm Video & 48 & 11 & Baofeng Group & $\begin{array}{l}\text { Galaxy } \\
\text { International } \\
\mathrm{TV}^{* *}\end{array}$ \\
\hline LeTV & 39 & 7 & LeEco (Le.com) & CNTV \\
\hline Baidu Video & 33 & 7 & Baidu & $\begin{array}{l}\text { Galaxy } \\
\text { International } \\
\mathrm{TV}\end{array}$ \\
\hline
\end{tabular}

Source: QuestMobile (2015), Zhao (2017) 
Note. 'Ownership' refers to the ultimate parent company of each video service. Although different corporate structures apply, each company is integrated into a larger enterprise. Galaxy International TV is a joint venture of Jiangsu Broadcasting Corporation, National Radio, and iQiyi. The data presented here support findings from other market research (e.g., China Internet Watch, 2017 and Yiguan Analysis, 2017). Despite their limitations, all these previous studies offered the same general conclusion regarding BAT dominance. 


\section{Figure}

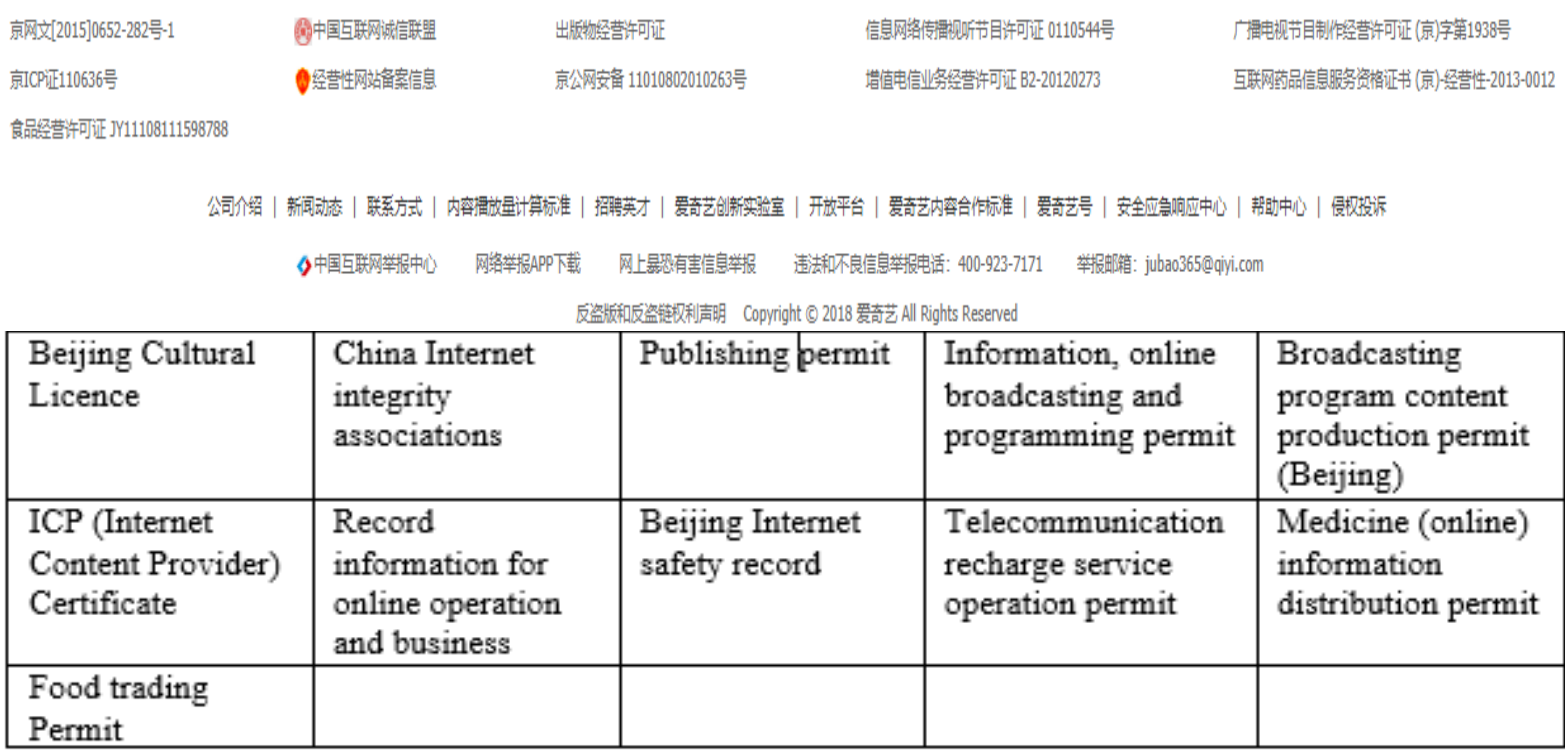

Figure 1. Licenses and permits displayed on the iQiyi website. Source: Screen capture by authors 